\title{
Competitive Pricing with Dynamic Asymmetric Price Effects
}

\author{
Chris K. Anderson, University of Western Ontario \\ Henning Rasmussen, University of Western Ontario \\ Leo MacDonald, Korean Advanced Institute of Science and Technology
}

\begin{abstract}
We model the temporal pricing strategies for two firms with asymmetric costs and differing market power (i.e. big-box retailer versus smaller local merchant). A firm's demand is a function of its price, a reference price and its competitor's price. Price effects may be asymmetric, i.e. consumers respond differently if they perceive a good to be over-priced versus underpriced. We derive analytical results for optimal prices. We show through a series of numerical examples under what settings firms choose various pricing strategies as well as profit implications for firms with differing costs.
\end{abstract}

\section{Introduction}

In this paper, we look to provide insight into price and profit effects associated with the development of big-box retailers. There has been a recent trend in the development of large retailers that actively promote their low prices, the most common example in North America is Wal-Mart or ASDA in the United Kingdom. Wal-Mart has achieved considerable cost advantages, then relays these cost savings to consumers with low prices. Conversely, there coexists numerous smaller retailers with higher cost structures and resultant prices. The higher cost firms may coexist with the low cost provider as consumers may place differing value on the purchasing experience at a large low-cost firm versus a service focused firm with higher costs and prices.

The application of revenue management and dynamic pricing to the retail sector has seen a rapid expansion in the last several years. Recent publications involving applications to the retail sector include Rajan and Steinberg (1992), Subrahmanyan and Shoemaker (1996), Bitran and Mondschein (1997), Smith and Achabal (1998), Federgruen and Heching (1999) and Zhao and Zheng (2000). However, a deficiency noted within the recent literature has been the lack of modeling with respect to the competitive environment (Bitran and Caldentey, 2003). The vast majority of price optimization and 
revenue management has focused on the monopolist problem, which is true of the retail literature listed above.

A separate area of research with respect to dynamic retail pricing and consumer demand found primarily in the marketing literature has been that of reference pricing. A list of recent papers include those by Winer (1986), Greenleaf (1995), Kopalle et al. (1996) and Fibich et al. (2003).A reference price is a base price for consumers resulting from the pricing environment. It is constructed by consumers through personal shopping experience and exposure to price information (Fibich et al., 2003). Reference prices are usually defined operationally as either the previous posted price or a function of recent posted prices, often as a weighted or smoothed average (Greenleaf, 1995). It is suggested that demand for a particular product depends not only on the price of the product but also on whether the price is above the reference price (a perceived loss) or below the reference price (a perceived gain) (Kopalle et al., 1996).

Differences in the reference price affect demand for a product negatively, if the reference price is above the posted price or positively if the posted price is less than the consumer's reference price. Reference prices result in a dynamic effect on the current demand rate, with a time lag on the demandprice response until consumers adjust the reference price to the new price (Fibich et al., 2005).

As a result of this dynamic effect, if the consumer values losses and gains differently (i.e. there is an asymmetric reference price response) then optimal prices may be cyclical as the retailer can achieve incremental profit from under- and over-pricing. This was shown by Greenleaf (1995) in a monopolistic environment with asymmetric reference prices, and extended to a duopoly by Kopalle et al. (1996).

As with the retail literature cited above, most of the reference price literature, with the exception of Kopalle et al. (1996) and Fibich et al. (2003) have considered monopolistic settings only. Kopalle et al. (1996) and Fibich et al. (2003) use a game theoretic approach to determine open-loop Nash equilibria for a duopoly. However, often the informational requirements for a game theoretic approach are not available nor easily ascertained or estimated (e.g. competitor sales and inventory). Both Kopalle et al. (1996) and Fibich et al. (2003) use a static treatment for competitor pricing with both firms having identical costs. Cellini and Lambertini (2004) study sticky prices under competitive situations, where similar to reference prices, market price is a function of past prices. Production quantities are the decision variables, with market prices determined by demand levels.

Related research that looks at asymmetric effects in competitive environments includes Souza(2004) and Laussel et al. (2004). Souza (2004) looks at product introductions in a duopoly, with prices determined exogenously for firms having potentially asymmetric product introduction costs. 
Laussel et al. (2004) studies price effects for markets with different sized firms, where firm size is linked to congestion. The example provided is an Internet service provider.

In Section 2, we develop a dynamic model of the smaller retailer pricing in a single market dominated by a larger retail chain. Consumers have different price expectations for the two firms and the two firms have different cost structures. Only the past posted prices of the competitor are available, as well as their own demand functions. Our specific interest is in the policies of the smaller retailer trying to compete when the market is dominated by the larger big-box retailer with a cost advantage. In Section 3, we examine various scenarios and derive 'optimal' strategies for the firm as a function of consumer price expectations and competitor pricing. Examples are provided in Section 4 with conclusions and future research discussed in Section 5.

\section{Dynamic Duopoly Model}

We develop a model for two firms pricing in one market. Optimal prices for the smaller firm will be illustrated in a two-firm setting, although the approach easily extends to a mixed multi-firm setting. Throughout the paper, the larger of the two firms (e.g. the big-box retailer) will be designated as Firm 1 and the smaller retailer as Firm 2.

The costs per unit inventory for both firms, $C_{1}$ and $C_{2}$, are fixed, with $C_{1}<C_{2}$. The length $T$ of the planning horizon is finite and relatively short, and as such no discounting of cash flows is required. Periodic reordering to replenish stocks occurs over this period, with demand met in each period, so inventory considerations would be minimal (such as salvage value) and are not included.

A firm can sell up to a maximum of $\mathrm{M}_{\mathrm{i}}(\mathrm{i}=1,2$ for Firms 1 and 2$)$ units of a durable good per period for a price that is set at the beginning of the period. $M_{i}$ can be taken as the maximum inventory available per period, say as a multiple of a number of periods' base demand, i.e. demand equivalent to that expected over $n$ periods.

\section{Demand Model}

We first develop a dynamic demand model that incorporates both reference price and competitive price effects in the current demand rate.

The impact of reference prices upon demand are usually included as additive. Greenleaf (1995) and Kopalle et al. (1996) use the form in (1) for demand $D_{t}$ in period $t$ : 
(1)

$D_{t}=\beta_{0}+\beta_{1} P_{t}+\beta_{2} P R G_{t}+\beta_{3} N R G_{t}$,

where $P R G_{t}=\max \left(P_{t}-r_{t}, 0\right)$ and $N R G_{t}=\min \left(P_{t}-r_{t}, 0\right)$ for price $P_{t}$ with $r_{t}$ being the reference price. The first two terms represent a standard additive demand model with linear price effects. The use of two reference price coefficients, $\beta_{2}$ and $\beta_{3}$, create an asymmetric response about $r_{t}$ when $\beta_{2} \neq \beta_{3}$.

Additive linear demand has also been utilized to capture the dynamics of competitive prices. A simple linear additive demand model incorporating competitive prices for two firms can be specified as:

(2)

$$
D_{i}\left(P_{i, t}, P_{j, t}\right)=\beta_{0}+\beta_{1} P_{i, t}+\gamma\left(P_{j, t}-P_{i, t}\right) \quad i, j=1,2 ; i \neq j,
$$

where subscript i denotes own price and demand and subscript $j$ denotes the competitor's price. A positive $Y$ indicates firm i demand increases if they price below firm j. Examples using linear additive demand of form (2) include Eliashberg and Steinberg (1991) and Dixit (1979).

Kopalle et al. (1996) used a combination of (1) and (2) to model both dynamic (internal) reference price effects and (external) competitor price effects jointly in a duopoly. The demand model for firm i was given as:

$$
D_{t}=a_{i}-b_{i} P_{i, t}+g_{i}\left(r_{i, t}-P_{i, t}\right)+\theta_{i, j} P_{j, t},
$$

where the first two terms are the standard linear additive demand model, the second term models the reference price effect, and the third term incorporates the competitor's price $\left(P_{j}\right)$ using a scaling factor $\left(\theta_{i, j}\right)$. The demand model can be rewritten as:

(4)

$$
D_{t}=a_{i}-b_{i}\left(\frac{\theta_{i, j}}{b_{i}} P_{j, t}-P_{i, t}\right)+g_{i}\left(r_{i, t}-P_{i, t}\right)
$$

so that the firm price and competitor price effects are incorporated into a single term similar to (2) given above.

The paper by Kopalle et al. (1996), which was expanded upon in Fibich et al. (2003), shows that for asymmetric reference price effects in a duopoly, the optimal pricing polices for both firms maybe constant (i.e everyday low-price) or cyclical, with firms alternating between higher and lower prices with 
respect to their competitor. The model for both papers assumed a downward sloping linear demandprice relationship, thus dynamic effects were limited to the reference price response as indicated in (3).

We propose a demand formulation in which the demand based upon differences in competitive prices also imposes a dynamic effect.

In the model the starting or base demand rate in each period is the past period demand, thus competitive price differences affect the underlying demand rate in subsequent periods. This is in contrast to the more standard static demand models where current demand effects of competitive prices are instantaneous (as in the additive demand formulation discussed above).

Specifically we begin with a log-linear model for demand with reference price effects where

$$
D_{i, t}=D_{i, t}\left(1-\frac{P_{i}}{P_{j}}, 1-\frac{P_{i}}{r_{i}}\right) .
$$

Log-linear or exponential demand functions are often utilized in inventory modeling and are commonly used in the empirical estimation of demand curves (Lau and Lau, 2003).

One representative form of the model may be given as:

$$
D_{i, t}=D_{i, t-1} \exp \left(\alpha_{i}\left(1-\frac{P_{i}}{P_{j}}\right)+\beta_{i}\left(1-\frac{P_{i}}{r_{i}}\right)\right) .
$$

Equation (6) meets the basic characteristic requirements for inclusion of the impact of pricing on the demand rate. A firm's demand in any period is affected negatively as they price $\left(P_{i}\right)$ above competition $\left(P_{j}\right)$ or consumer's expectation of prices (i.e. the reference price $\left.r_{i}\right)$ in any period $t$.

We take the demand rate as constant for each period and update it at the end of the period based upon the competitive and reference price effects, which then becomes the base demand rate for the next period.

The values of the two parameters $\alpha$ and $\beta$ model the importance of the relative price differences on the current period's demand rate. If $\alpha$ is large, it indicates that consumers are aware of and sensitive to the price differential between the two firms. $\beta$ on the other hand models the reluctance of consumers to buy if perceived prices are too high. $B=0$ implies that demand only depends on prices relative to the competition. Similarly, if $\alpha=0$ for either firm, then the firm only has to consider reference price effects on its demand rate.

Additionally we suppose that response to competitive pricing can be asymmetric, 
$\alpha_{i}= \begin{cases}\alpha_{i, 1} & \text { if } P_{i}<P_{j}, \\ \alpha_{i, 2} & \text { if } P_{i}>P_{j}\end{cases}$

where $\alpha_{i, 1}$ represents a perceived 'gain' by the consumer, and $\alpha_{i, 2}$ is perceived as loss relative to the competitor's price.

For ease of comparative results, we assume that reference price effects are symmetric. See Kopalle et al. (1996) and Fibich et al. (2003) for analysis of asymmetric $\beta$ in a duopoly. Consistent with previous research (Kopalle et al., 1996; Greenleaf, 1995) exponential smoothing is used for updating reference prices from period to period. Thus, the reference price for a subsequent period for firm $i$ is given as:

(7)

$$
r_{t}=\theta_{i} r_{i, t-1}+\left(1-\theta_{i}\right) P_{i, t-1}
$$

where $0 \leq \theta \leq 1$, with $\theta=1$ indicating a constant reference price, and $\theta=1$ resulting in a reference price equivalent to the last period's posted price.

Profit Model

Let $D_{i, t}=D_{i, t}\left(P_{i, t}, P_{j, t}, r_{i, t}\right)$ be the rate at which inventory is sold by company $i$ in period ' $\mathrm{t}$ ', where $i, j=1,2$ and $i \neq j$. The profit for firm $i$ over a time interval $t_{0}<t<t_{1}$ is then,

(8)

$$
R_{i, t}=\left(P_{i, t}-C_{i}\right) D_{i, t}\left(P_{i, t}, P_{j, t}\right) \Delta T
$$

where $\Delta T=t_{1}-t_{0}$.

The sales for a period cannot be greater than $M_{i, t}$, thus

(9)

$$
D_{i, t} \Delta T \mid \leqslant M_{i, t}
$$

We will discuss this restriction further in a subsequent section.

Assuming a durable good with periodic replenishment of inventory and an ability to sell in a subsequent period, we restrict 
(10)

$$
P_{i}>C_{i} \text {. }
$$

Firm $i$ is looking to determine its price for the coming period $P_{i, t}$ so as to maximize revenue $R_{i, t}$ in that period, with the two firms $(i=1,2)$ potentially facing different market forces and demands.

The profit per period is given as

$$
R_{i, t}=\left(P_{i, t}-C_{i}\right) D_{i, t}\left(P_{i, t}, P_{j, t}\right) \Delta T .
$$

We will suppose that demand coefficients and prices are constant for each period. We now want to determine a price $P_{i, t}$ which maximizes (11), subject to the two constraints

$$
D_{i, t} \Delta T \leqslant M_{i, t}, \quad P_{i, t}>C_{i} .
$$

\section{Pricing Decisions}

Based upon available information and the competitive response (or lack thereof), various pricing strategies are available to Firm 2 (as well as Firm 1). We describe three potential situations and subsequent strategies and evaluate the implications for the smaller retailer coexisting in the same market as the major/big-box competitor.

Scenario 1: Although small with respect to market share, the prices of Firm 2 are reflected in that of Firm 1. Both firms thus act in direct price competition.

Scenario 2: Firm 2, being the smaller retailer, sets its prices for the upcoming period after Firm1 has posted its price. In this scenario, Firm 1 recognizes Firm 2 as a competitor and still competes on price, but regards Firm 2's strategies as relatively insignificant, reflecting its lack of power in the market relative to Firm 1.

Scenario 3: Firm 1 mainly prices goods based upon reference price effects (i.e. $\alpha_{1,1}$ and $\alpha_{1,2}$ are small relative to $\beta$ and $\alpha_{2,1}$ and $\alpha_{2,2}$, and does not concern itself with Firm 2 . Firm 2 still pricesbased upon both competitive and reference price effects.

Both symmetric and asymmetric consumer response to competitive prices are considered, as well as different exponential smoothing levels $(y)$ for updating the reference price per period for each firm. 


\section{Simultaneous Pricing Approach}

Both firms price optimally based on their knowledge of the competitor's price from the previous period. The two companies must determine their prices for a given interval, say a week in advance, where they do not know what the other company is charging, their inventory or what strategies they may employ. During this period, the prices set are fixed. Thus company $i$ must decide on its new price on the first day of the interval and the only knowledge it has about company $j$ is that it knows what $P_{j}$ was in the previous period. These conditions apply to scenarios 1 and 3 discussed above.

We use the old value of $P_{j}\left(i . e . P_{j, t-1}\right)$ and calculate an 'optimum' price $P_{i}$ for the coming period t. A similar calculation will be carried out for company j using the previous period value $P_{i, t-1}$.

Let us divide the interval 04t4T into $\mathrm{N}$ subintervals of length DT such that subinterval 1 is defined by

$0=t_{1} \leqslant t \leqslant t_{2}$

In general the $n$th subinterval is defined by

$$
t_{n} \leqslant t \leqslant t_{n+1},
$$

where $t_{n}=n \Delta T$. Thus if $T$ is 12 weeks and $\Delta T$ is a week, $N$, the total number of subintervals, is 12 .

Consider now the $n$th subinterval. We will now suppose that $P_{1}$ is constant during this intervaland that we do not know what $P_{2}$ is going to be, but in our calculations we use the price from the previous interval, i.e. $P_{2, n-1}$.

In the first period we do not have a price for the previous period, so we will suppose that the demand model does not depend on either $P_{1,0}$ or $P_{2,0}$, i.e. $\alpha=0$. The computation proceeds in the following manner. We solve the optimization problem for $P_{1,1}$ and this price will be used throughout the interval, performing a similar calculation for $P_{2,1}$. In the second period, Firm 1 will know $P_{1,1}$ and use it to estimate an optimal $P_{1,2}$. Similarly, Firm 2 will know $P_{2,1}$ and use it to calculate the optimal $P_{2,2}$. This process will be repeated for the remaining intervals, with updatingof demand rates and reference prices based upon equations (6) and (7), respectively.

Sequential Pricing Approach

In sequential pricing, for each period, Firm 2 observes Firm 1's posted price for the upcoming period before having to determine its price. The approach is equivalent to that given above for 
simultaneous pricing, with the current period's price for Firm 1 substituted into the calculations for Firm 2. These conditions apply to scenario 2 as described at the beginning of this section.

Optimal Price Estimates - Symmetric Response

Let us first suppose that the response to the competitor's price is symmetric. Note that for Firm 2 , the approach as described below is based upon simultaneous pricing, with similar calculations, modified as described in the preceding section, performed under sequential pricing conditions.

For the symmetric response we have

$$
\alpha_{i, 1}=\alpha_{i, 2}=a
$$

Then as shown in the Appendix the optimal price is either

$$
P_{i, t}=C_{i}+\frac{1}{\gamma}
$$

when $D_{i, t} \Delta T \leq M_{i, t}$ or

$$
P_{i, t}=\frac{1}{\gamma}\left(\alpha_{i}+\beta_{i}-\log \left(\frac{M_{i, t}}{D_{i, t-1} \Delta T}\right)\right),
$$

where

$$
\gamma=\frac{\alpha_{i}}{P_{j, n-1}}+\frac{\beta_{i}}{r_{i, t}}
$$

when $D_{i, t} \Delta T>M_{i, t}$.

We can now calculate the estimated sales and profits using these two prices. For the coming period we use the price and corresponding sales that gives the highest profit within the constraints given in (12). Note that the price for the case when the sales constraint is not binding can be interpreted as an example of the standard cost-plus rule, i.e. the optimal price is the cost $C_{i}$ plus a mark up which depends upon competitive prices $\left(P_{j, t}\right)$, consumers' price expectations $\left(r_{i, t}\right)$, and two model parameters $\alpha$ and $\beta$. 


\section{Optimal Price Estimates - Asymmetric Response}

The situation is more complicated when the response to the competitor's price is asymmetric, i.e. when $\alpha$ takes on different values depending on $P_{i}$ being greater or less than $P_{j}$. Again calculations are shown for the simultaneous pricing situation, with similar calculations available to the sequential pricing case where Firm 2 uses the current period's price for Firm 1.

Let us first consider the case when $D_{i, t} \Delta T \leq M_{i, t}$. For period $n$, we have two values of $P_{i, n}$ :

$$
P_{i, n}^{1}=C_{i}+\frac{1}{\gamma_{1}}
$$

and

$$
P_{i, n}^{2}=C_{i}+\frac{1}{\gamma_{2}},
$$

where

$$
\gamma_{m}=\frac{\alpha_{i, m}}{P_{j, n-1}}+\frac{\beta_{i}}{r_{i}}, \quad m=1,2
$$

If $\propto_{i, 1} \geq \propto_{i, 2}$ then $P_{i, n}^{1} \leq P_{i, n}^{2}$. Thus, we now have two cases to consider.

1. If $P_{i, n}^{1}>P_{j, n-1}$ then $P_{i, n}^{2}>P_{j, n-1}$ so $P_{i, n}=P_{i, n}^{2}$ as given above.

2. If $P_{i, n}^{1}<P_{j, n-1}$, then either $P_{i, n}^{2}<P_{j, n-1}$ or $P_{i, n}^{2}>P_{j, n-1}$

If $P_{i, n}^{2}<P_{j, n-1}$ then $P_{i, n}=P_{i, n}^{1}$. If $P_{i, n}^{2}>P_{j, n-1}$ compare the estimated profits $R_{i, n}^{1}$ and $R_{i, n}^{2}$. If $R_{i, n}^{1}>R_{i, n}^{2}$ then $P_{i, n}=P_{i, n}^{1}$. Otherwise $P_{i, n}=P_{i, n}^{2}$

Let us now consider the case when $D_{i, t} \Delta T=M_{i, t}$, that is we have a binding constraint on sales for the period $t$. Now we have two values of $P_{i, n}$ : 
(17)

$P_{i, n}^{1}=\frac{\alpha_{i, 1}+\beta_{i}}{\gamma_{1}}-\frac{1}{\gamma_{1}} \log \frac{M_{i, n}}{D_{i, n-1} \Delta T}$,

(18)

$$
P_{i, n}^{2}=\frac{\alpha_{i, 2}+\beta_{i}}{\gamma_{2}}-\frac{1}{\gamma_{2}} \log \frac{M_{i, n}}{D_{i, n-1} \Delta T} .
$$

This results in four possible cases to consider.

1. If $P_{i, n}^{1}<P_{j, n-1}$ then $P_{i, n}^{2}>P_{j, n-1}$. Then

$$
P_{i, n}=P_{i, n}^{1} \text {. }
$$

2. $P_{i, n}^{1}>P_{j, n-1}$ and $P_{i, n}^{2}>P_{j, n-1}$. Then

$$
P_{i, n}=P_{i, n}^{2} \text {. }
$$

3. If $P_{i, n}^{1}<P_{j, n-1}$ and $P_{i, n}^{2}>P_{j, n-1}$. Then if $R_{i, n}^{1}>R_{i, n}^{2}$

$$
\begin{aligned}
& P_{i, n}=P_{i, n}^{1} \\
& \text { If } R_{i, n}^{1}<R_{i, n}^{2} \\
& P_{i, n}=P_{i, n}^{2} .
\end{aligned}
$$

4. $P_{i, n}^{1}>P_{j, n-1}$ and $P_{i, n}^{2}<P_{j, n-1}$. It is easily shown that this cannot occur.

For given values of the different parameters we now have two different estimates of the optimal value of $P_{i, n}$, where either the sales constraint is binding or not binding. Using these we calculate the corresponding values of the estimated profits and select the value of $P_{i, n}$ which results in the larger profit.

\section{Numerical Examples}

\section{Simultaneous Pricing}

We will first consider the case where there are two competing firms, potentially with different cost structures, specifically $C_{1}<C_{2}$, and different reference prices $\left(r_{1} \neq r_{2}\right)$. We assume that the two companies post new prices simultaneously at the beginning of each period. For example, we could have 12 weeks and each company advertises their new prices in a weekend flyer or advertisement. Except for the first period both companies will know the price that their competitor used in the previous week. For the first period this information is not available so we set $\propto_{1}$ and $\propto_{2}$ equal to zero. When comparing 
sales and profits we use only the last six periods to remove transient or start-up effects resulting from the selection of initial values. We model reference prices as a constant $(\theta=1)$, as the last posted price $(\theta=0)$ as well as a smoothed average of recent prices $(\theta=0.5)$. Table 1 lists base parameter values, where $\alpha_{2}=3$ represents an asymmetric consumerresponse to a competitive price differential, and $\alpha_{2}=5$ indicates a symmetric response.

Figure 1 displays sample price paths for the smaller retailer (Firm 2) under symmetric and asymmetric competitive pricing conditions. Three series in the figure display prices converging to a constant level, with all involving a symmetric a. Of these series, the series (labelled constant) with a constant reference price $(\theta=1)$, set at 0.72 or $20 \%$ above cost, results in a higher fixed or stable price than the other two series.

The 'smoothed' series displays prices for an exponentially smoothed price $(\theta=0.5)$ and the 'last' series displays prices in which the reference price is equal to the previous period's price $(\theta=0)$. When reference prices are updated in either of these manners, we see that both prices converge to the same fixed price, which will be equivalent to the reference price.

Under a constant reference price, the firm sets its price below the reference price, balancing return per unit sales with increased total demand resulting from reference price effects, to maximize profits. When the reference price is the last posted price or a smoothed combination of past prices, the firm sells fewer units, with a demand of 10.0 units per period as opposed to the14.2 units per period for the constant reference price case, and achieves lower overall profits.

Table 1

Base case parameter values

\begin{tabular}{lclc}
\hline Parameter & Value & Parameter & Value \\
\hline$\beta_{1}$ & 5 & $\beta_{2}$ & 5 \\
$\alpha_{1}$ & 5 & $\alpha_{2}$ & 3,5 \\
$D_{1,0}$ & 100 & $D_{2,0}$ & 10 \\
$M_{1}$ & 300 & $M_{2}$ & 30 \\
$C_{1}$ & 0.6 & $C_{2}$ & 0.6 \\
$r_{1,0}$ & $1.2 C_{1}$ & $r_{2,0}$ & $1.2 C_{2}$ \\
\hline
\end{tabular}




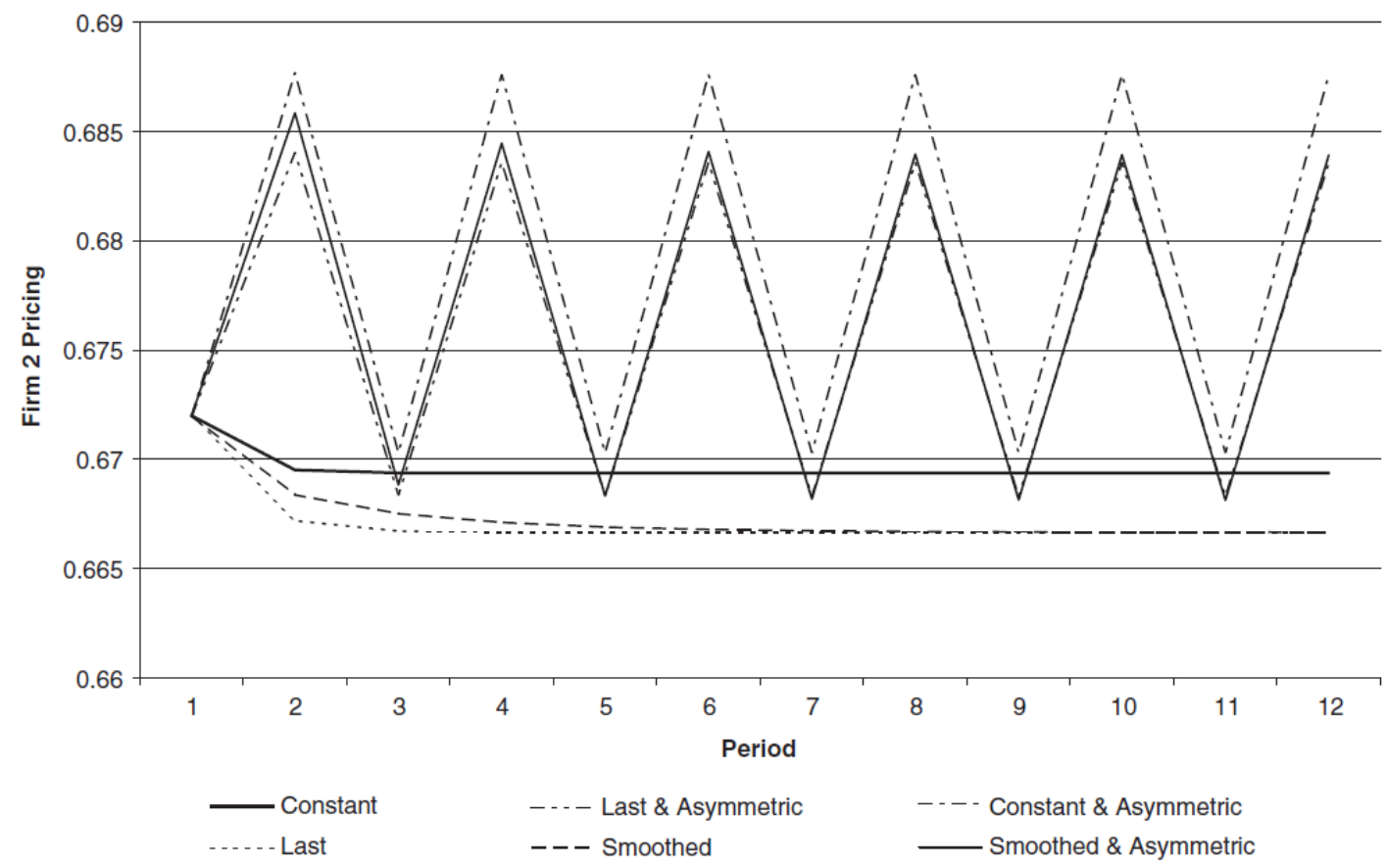

Fig. 1. Optimal price paths for Firm 2.

The other three series in Fig. 1 display cyclical pricing, with these series having an asymmetric consumer response to competitor prices. The asymmetry results in a larger increase in demand when pricing below the competition versus the corresponding decrease with a comparable price differential above a competitor's price.

The price differentials in a cycle for all three series are similar, with the results of the constant reference pricing having the highest overall prices. Sales for the constant reference price are below that experienced under similar conditions with a symmetric competitive price response, with average sales of 13.3 units per period.

As above, both the smoothed reference price and last reference price effects result in both converging to the same prices in each period. Sales are again lower when reference prices are adjusted (i.e. smoothed or last posted price) as compared with a constant consumer reference price, with the average being the same for both cases as that for a symmetric demand response at10.0 units per period.

Overall higher prices are observed for the asymmetric situation, in which the retailers use the asymmetric price effects on the demand rate to extract additional revenues.

Figure 2 displays price paths similar to Fig. 1 under equivalent conditions except Firm 1 has a10\% cost advantage on purchased inventory. Under symmetric conditions, the price trajectories are similar, but lower, to those in Fig. 1 for the symmetric cases. The main difference occurs when there are 
asymmetric price effects. Under this scenario the price trajectories converge to a fixed price versus oscillate as observed when no cost advantage was present. The big-box firm (Firm 1) in this situation continuously prices below competition, no longer trying to extract extra profit through the cycling of prices/demand, using its cost advantage to restrict Firm 2's pricing strategies.

Firm 2 prices higher to extract a maximum profit, although resulting in reduced sales and a lower overall profit than that realized when Firm 1 did not have a cost advantage. Firm 1 is able to increase both its sales and profits by leveraging its cost advantage.

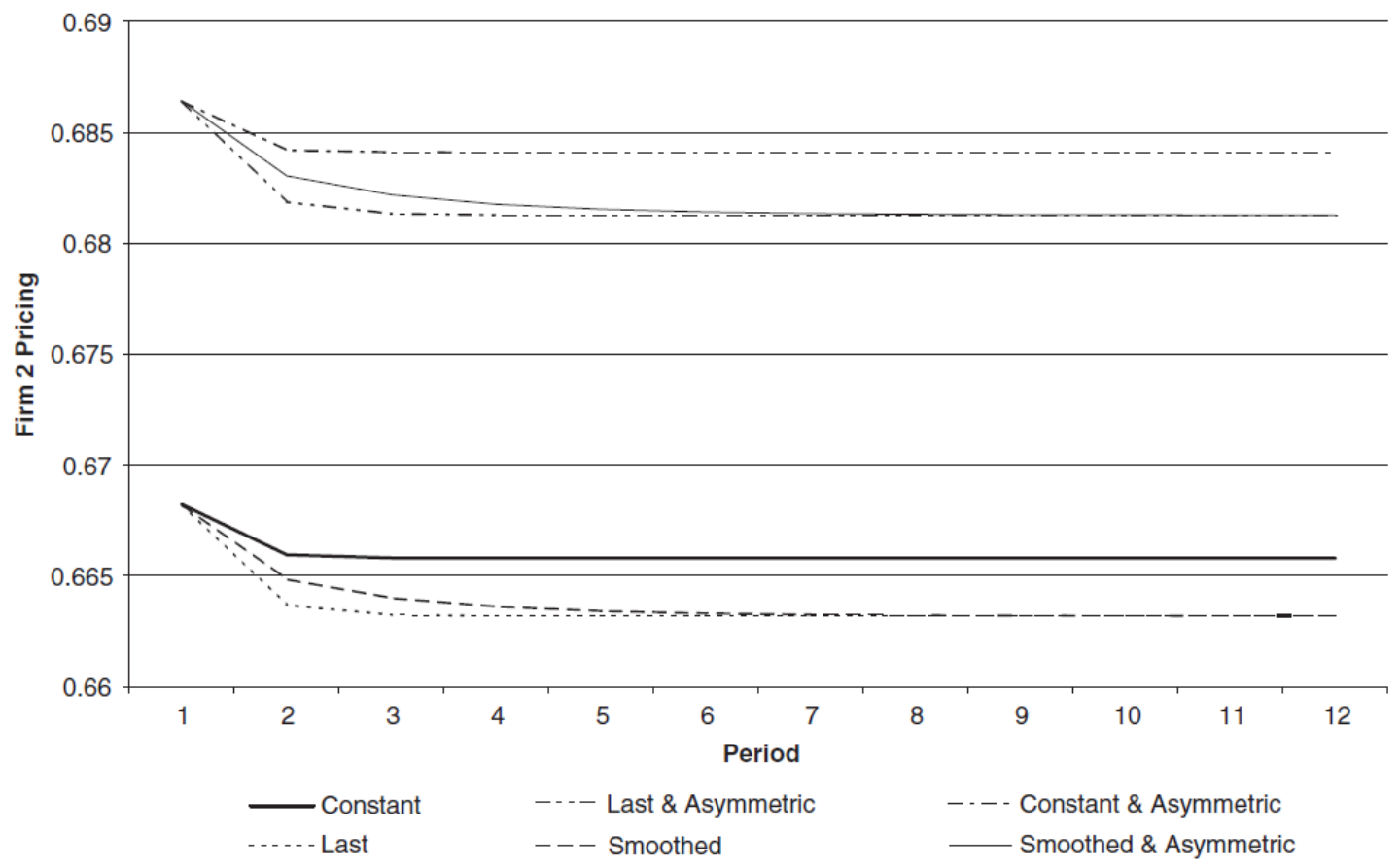

Fig. 2. Optimal price paths for Firm 2 with cost differential.

Table 2 displays the average (of last six periods) per period demand and profit for Firm 2, with and without a Firm 1 cost advantage. With no cost differential between the two firms and when the response to competitor pricing is asymmetric, both firms cycle their prices. This results in overall higher prices but with increased sales as well as increased profits of approximately $1-13.4 \%$ over the symmetric case.

When Firm 1 has a cost advantage it prices to sell additional inventory while also increasing its profits. This results in a fixed lower price for Firm 1, forcing Firm 2 to follow, dropping its own price, although Firm 2 cannot match Firm 1's price. Firm 2's price decreases also, but sales still decrease resulting in a marked drop in per period profits. This is consistent under conditions of symmetric and asymmetric competitive price response, as well as various reference price effects, with profit dropping 
41.4-43.3\% under symmetric conditions and $26-26.7 \%$ when competitive pricing effects are asymmetric.

Table 2

Firm 2 per period demand and profit - simultaneous pricing

\begin{tabular}{|c|c|c|c|c|}
\hline \multirow[b]{2}{*}{ Scenario } & \multicolumn{2}{|l|}{$C_{1}=C_{2}$} & \multicolumn{2}{|l|}{$C_{1}<C_{2}$} \\
\hline & Demand & Profit & Demand & Profit \\
\hline \multicolumn{5}{|l|}{ Symmetric $\alpha$ 's } \\
\hline Constant & 14.2 & 0.99 & 8.9 & 0.58 \\
\hline Smoothed & 10 & 0.67 & 6.1 & 0.38 \\
\hline Last & 10 & 0.67 & 6.1 & 0.38 \\
\hline \multicolumn{5}{|c|}{ Asymmetric $\alpha$ 's } \\
\hline Constant & 13.2 & 1.0 & 8.7 & 0.74 \\
\hline Smoothed & 10 & 0.76 & 6.8 & 0.56 \\
\hline Last & 10 & 0.75 & 6.8 & 0.55 \\
\hline
\end{tabular}

\section{Sequential Pricing}

In this section, we address the situation where Firm 2 has the advantage, as the smaller retailer, to react to Firm 1's posted prices for the upcoming period before posting its price (e.g. has a shorter lead time for advertising). For clarity we present and compare only one set of reference price results from the simultaneous pricing case, where the reference price is taken as the last period's posted price $(\theta=0)$. Both symmetric and asymmetric competitor price effects are included. Thus the values shown in Table 3 for the simultaneous results are the same as that for Table 2 for 'Last.'

Figure 3 compares the price paths for the four cases. In both situations where Firm 1 enjoys a cost advantage, this effect dominates and forces a fixed price on Firm 2, regardless of asymmetric competitive price responses. The pricing in these two cases actually converge to the same level. More interesting is the situation where no cost advantage is present. Under simultaneous pricing, this had led to oscillating prices, although when Firm 2 has an informational advantage, it no longer uses cyclical pricing to extract additional profits, but instead chooses a fixed pricing scheme.

Demand and profit results are presented in Table 3 (again using an average of the last six periods). As above in Fig. 3, values shown in Table 3 for the simultaneous results are the same as that for Table 2 for 'Last.'

From Table 3, we see that without a cost advantage, Firm 2 is able to extract a slight increase in profit (4\%) by posting its price after its competitor, although sales are slightly reduced from 10 units per period to 9.2 units over the same interval. It does this using a higher price than that without similar informational advantages (see Fig. 3). However, when Firm 1 again has a cost advantage, we see that 
prices, sales, and profits converge to the same values. Firm 1's cost/pricing power enables it to dominate Firm 2's pricing strategies regardless of the added pricing information available to Firm 2.

Table 3

Firm 2 per period demand and profit - sequential pricing

\begin{tabular}{lccccc}
\hline & \multicolumn{2}{c}{$C_{2}=C_{1}$} & & \multicolumn{2}{c}{$C_{2}<C_{1}$} \\
\cline { 2 - 3 } Scenario & Demand & Profit & & Demand & Profit \\
\hline Simultaneous pricing & 10 & 0.75 & 6.8 & 0.55 \\
Sequential pricing & 9.2 & 0.78 & 6.8 & 0.55 \\
\hline
\end{tabular}

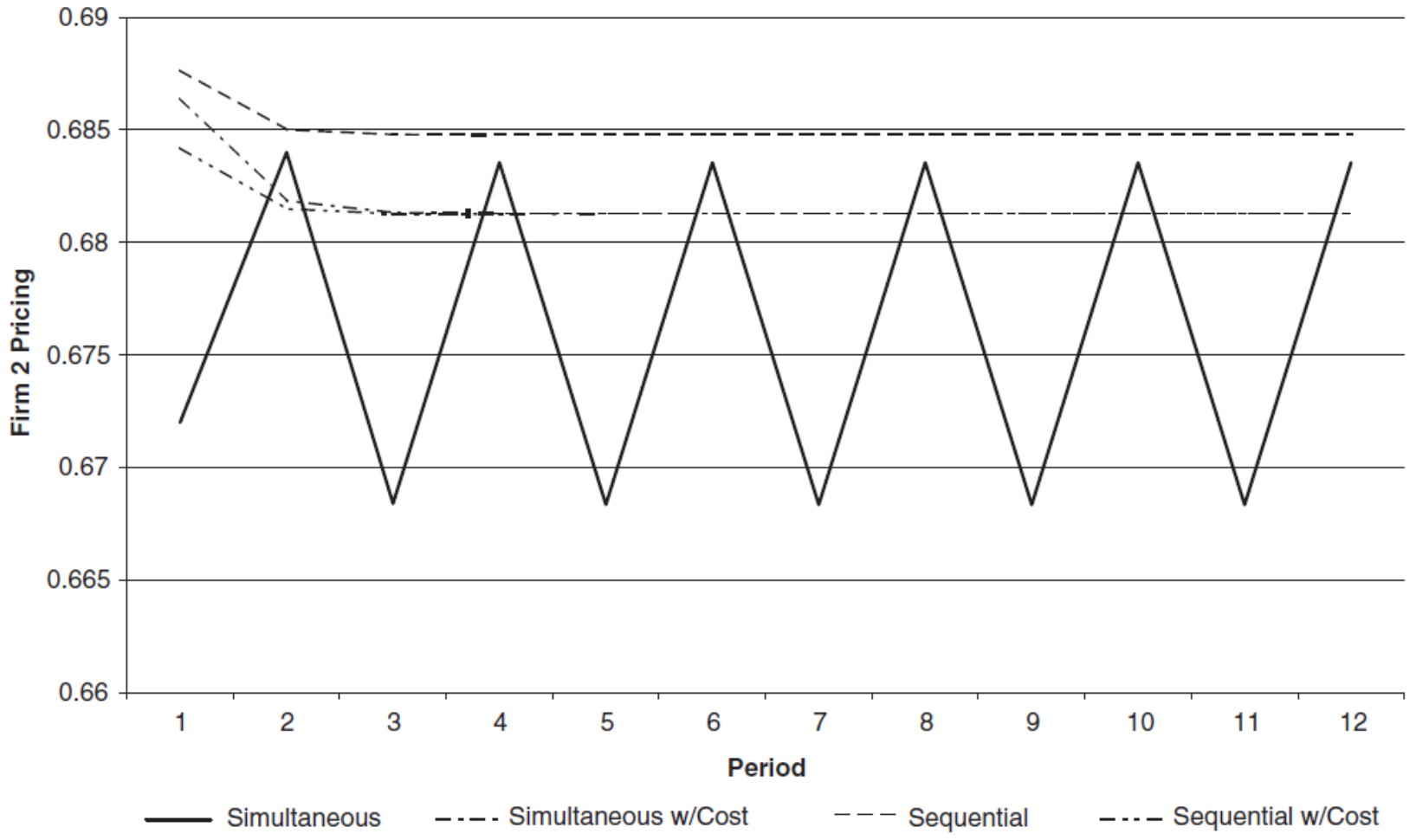

Fig. 3. Comparison of price paths under simultaneous and sequential pricing.

\section{Dissimilar Competitive Price Effects}

A final situation for analysis is where the response to price differential between the two firms are dissimilar, specifically where Firm 2's price has limited impact on Firm 1's demand (dominant market position), thus $\propto_{1}$ and $\propto_{2}$ are much lower for Firm 1 than Firm 2. We use values for Firm 1that are $20 \%$ that of Firm 2. Again we take only a single reference price effect $(\theta=0)$ and use the asymmetric price response $\left(\propto_{1}>\propto_{2}\right)$. 
The pricing results for the four cases are shown in Fig. 4 for comparison. With no significant price competition effects on Firm 1's demand, its overall price increases along with its realized profits with or without a cost advantage. However, this results in mixed lower/higher average overall and fixed pricing strategies by Firm 2 .

Specifically, where no cost advantage is assumed, Firm 2 uses a fixed price strategy, as opposed to the high/low pricing when equivalent competitive price response between firms is assumed, with a price below the average price under base case conditions. This results in increased sales, which also result in increased profits, although average returns on per unit sales are lower (see Table 4 for details).

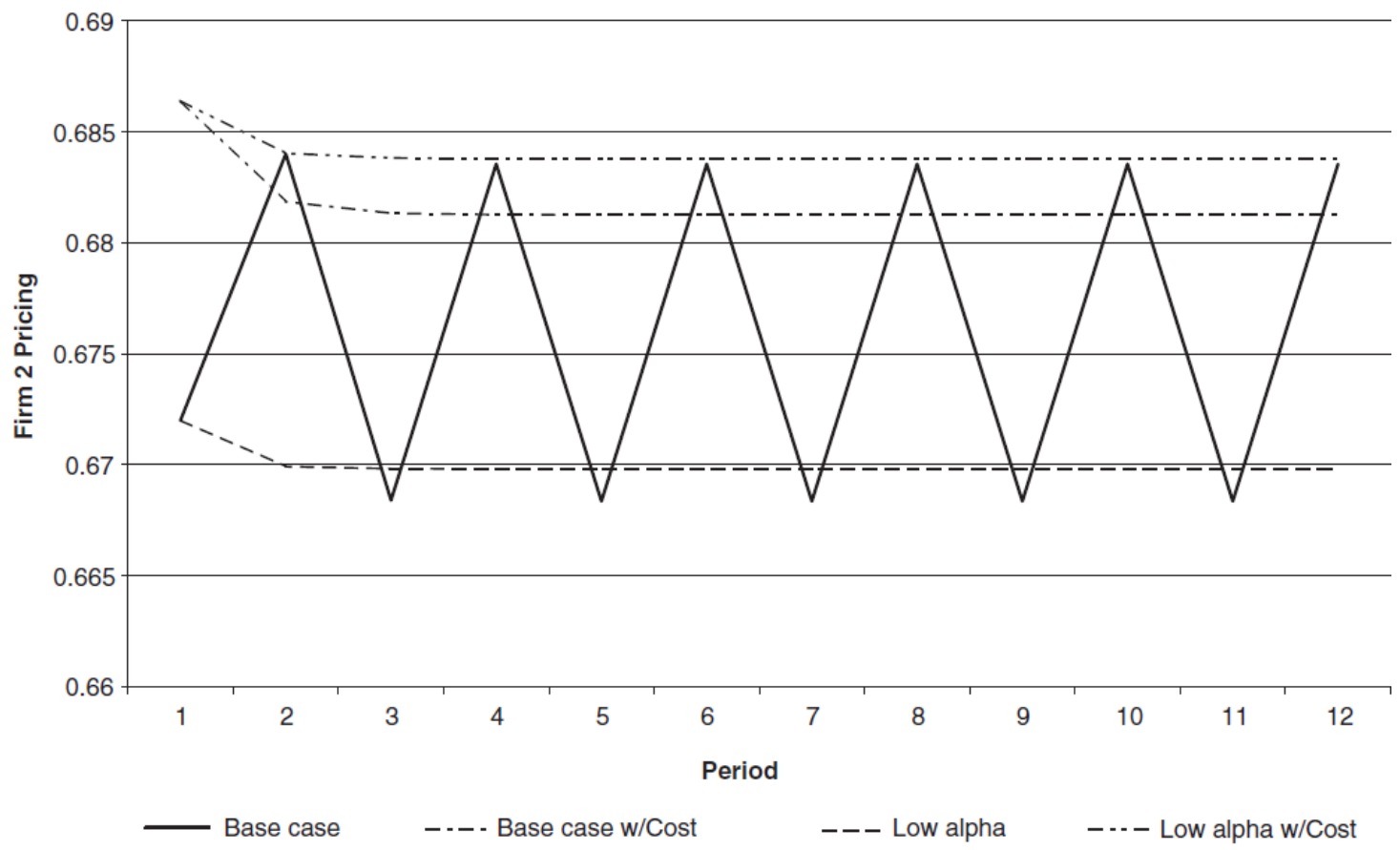

Fig. 4. Comparison of price paths with dissimilar competitive price response.

Table 4

Firm 2 per period demand and profit - dissimilar price response

\begin{tabular}{lllll}
\hline & \multicolumn{2}{c}{$C_{2}=C_{1}$} & & \multicolumn{2}{c}{$C_{2}<C_{1}$} \\
\cline { 2 - 3 } \cline { 5 - 5 } Scenario & Demand & Profit & Demand & Profit \\
\hline Equivalents $\alpha$ 's & 10 & 0.75 & 6.8 & 0.55 \\
Dissimilar $\alpha$ 's & 12.8 & 0.85 & 8.5 & 0.71 \\
\hline
\end{tabular}

When Firm 1 has a cost advantage, and significantly reduces its price compared with the equivalent inventory cost scenario, Firm 2 raises its price as compared with that under similar conditions when $\alpha$ values are the same for both firms. However, comparable sales and profits are still higher 
because of the higher overall price posted by Firm 1, although lower than that obtained when $C_{1}=C_{2}$ as the lower price/costs of Firm 1 force Firm 2 to decrease the price differential.

\section{Conclusion}

We have developed a relatively straightforward model to investigate aspects of pricing in a dynamic competitive environment. We were motivated by the divergence in retail offerings and the cost effectiveness gained through scale by large retailers and its impact upon smaller firms competing in the same market. It should be noted that although we initially imposed per period sales constraints on both firms, under none of the conditions tested were these constraints binding, and therefore did not impact the results.

Our analytical results provide foundation for a cost plus approach to pricing. Also, as observed in practice, it is indicated that smaller firms with higher cost structures can compete successfully in the same market when consumers put less pressure on competitive pricing. This final result indicates that large big-box stores and smaller service focused retailers can co-exist.

Interestingly, when consumers' responses to prices are asymmetric (treating bargains differently to high prices), a high-low strategy may be preferred by smaller retailers, dependent upon cost advantages of the larger firm as well as 'informational' advantages available to the smaller firm. Thus cyclical pricing strategies may be observed where the demand rate is affected by dynamic competitive pricing, similar to that shown in the literature for asymmetric reference price effects. However, numerical results indicate that different inventory costs as well as asymmetric market power can affect the optimality of this cyclical pricing strategy even if the price response is asymmetric.

Our model leaves several areas for future investigation. These include the impact of uncertainty upon a competitive pricing strategy as well as combined asymmetric effects towards reference prices simultaneously with those of competitive effects. Other areas include comparison of standard dynamic programming solutions for Firm 2 when Firm 1 is assumed to use a known fixed low-cost pricing strategy.

\section{References}

Bitran, G., Caldentey, R., 2003. An overview of pricing models for revenue management. Manufacturing and Service Operations Management, 5, 203-229. 
Bitran, G., Mondschein, S., 1997. Periodic pricing of seasonal product in retailing. Management Science, 43, 427-443.

Cellini, R., Lambertini, L., 2004. Dynamic oligopoly with sticky prices: closed-loop, feedback and openloop solutions. Journal of Dynamical and Control Systems, 10, 303-313.

Dixit, A., 1979. A model of duopoly suggesting a theory of entry barriers. The Bell Journal of Economics, $10,20-32$.

Eliashberg, J., Steinberg, R., 1991. Competitive strategies for two firms with asymmetric production cost structures. Management Science, 37, 1452-1473.

Federgruen, A., Heching, A., 1999. Combined pricing and inventory control under uncertainty. Operations Research, 47, 454-475.

Fibich, G., Gavious, A., Lowengart, O., 2003. Explicit solutions of optimization models and differential games with nonsmooth (asymmetric) reference price effects. Operations Research, 51, 721-734.

Fibich, G., Gavious, A., Lowengart, O., 2005. The dynamics of price elasticity of demand in the presence of reference price effects. Journal of the Academy of Marketing Science, 33, 66-78.

Greenleaf, E.A., 1995. The impact of reference price effects on the profitability of price promotions. Marketing Science, 14, 82-104.

Kopalle, P.K., Rao, A.G., Assuncao, J., 1996. Asymmetric reference price effects and dynamic pricing policies. Marketing Science, 15, 60-85.

Lau, A., Lau, H., 2003. Effects of a demand-curve's shape on the optimal solutions of a multi-echelon inventory/pricing model. European Journal of Operational Research, 147, 530-548.

Laussel, D., de Montmarin, M., Van Long, N., 2004. Dynamic duopoly with congestion effects. International Journal of Industrial Organization, 22, 655-677.

Rajan, A., Steinberg, R.R., 1992. Dynamic pricing and ordering decisions by a monopolist. Management Science, 38,240-262.

Smith, S., Achabal, D., 1998. Clearance pricing and inventory policies for retail chains. Management Science, 44, 285-300.

Souza, G.C., 2004. Product introduction decisions in a duopoly. European Journal of Operational Research, 152, 745-757.

Subrahmanyan, S., Shoemaker, R., 1996. Developing optimal pricing and inventory policies for retailers who face uncertain demand. Journal of Retailing, 72, 7-30.

Winer, R., 1986. A reference price model of brand choice for frequently purchased products. Journal of Consumer Research, 13, 250-256. 
Zhao, W., Zheng, Y., 2000. Optimal dynamic pricing for perishable assets with nonhomogeneous demand. Management Science, 46, 375-388.

\section{Appendix}

The optimization problem, for a firm choosing price $P_{i, n}$, with units costs $C$ and $D_{i, n}(P)$, can be stated as:

Find $P_{i, n}$ for period ' $n$ ' so that

$$
R_{i, n}=\left(P_{i, n}-C\right) D_{i, n} \Delta T
$$

is a maximum subject to the constraints $P_{i, n} \geq C$ and $D_{i, n} \Delta T \leq M_{i, n}$ where

$$
D_{i, n}=D_{i, n-1} \exp \left(\alpha_{i}\left(1-\frac{P_{i, n}}{P_{j, n}}\right)+\beta\left(1-\frac{P_{i, n}}{r_{i, n}}\right)\right),
$$

where $P_{j, n}$ is the competitor's price and $r_{i, n}$ the consumer's reference price (for our product/service). Define $L$ by

$$
L=\left(P_{i, n}-C\right) D_{i, n} \Delta T+\lambda_{1}\left(-P_{i, n}+C+s_{1}\right)+\lambda_{2}\left(D_{i, n} \Delta T-M_{i, n}+s_{2}\right)
$$

where $\lambda_{1}$ and $\lambda_{2}$ are the Lagrange multipliers and $s_{1}$ and $s_{2}$ are slack variables.

We note that

$$
\frac{\partial D_{i, n}}{\partial P_{i, n}}=-\gamma D_{i, n}
$$

where

$$
\gamma=\frac{\alpha_{i}}{P_{j, n}}+\frac{\beta}{r_{i, n}}
$$

Now, 


$$
\begin{aligned}
& \frac{\partial L}{\partial P_{i, n}}=D_{i, n} \Delta T-\gamma\left(P_{i, n}-C\right) D_{i, n} \Delta T-\lambda_{1}-\lambda_{2} \gamma D_{i, n} \Delta T=0 \\
& \frac{\partial L}{\partial \lambda_{1}}=-P_{i, n}+C+s_{1}=0 \\
& \frac{\partial L}{\partial \lambda_{2}}=D_{i, n} \Delta T-M_{i, n}+s_{2}=0 \\
& \frac{\partial L}{\partial s_{1}}=2 \lambda_{1} s_{1}=0 \\
& \frac{\partial L}{\partial s_{2}}=2 \lambda_{2} s_{2}=0
\end{aligned}
$$

1. For this case we take $s_{1}=0$ so $\lambda_{1} \neq 0$ and it is clear that the optimal value of $P_{i, n}$ is $P_{i, n}=C$.

Now if $s_{2}=0$ we see that $D_{i, n} \Delta T=M_{i, n}$ which is not compatible with $P_{i, n}=C$. Thus we take $s_{2} \neq 0$ and $\lambda_{2}=0$.

2. Now we take $s_{1} \neq 0$ so $\lambda_{1}=0$. If $s_{2}=0, P_{i, n}$ is the solution to $D_{i, n} \Delta T=M_{i, n}$ so the optimal value of $P_{i, n}$ is $P_{i, n}=\frac{1}{\gamma}\left(\alpha_{i}+\beta-\log \frac{M_{i, n}}{D_{i, n-1} \Delta T}\right)$. If $\lambda_{2}=0$ the optimal value of $P_{i, n}$ is the solution to the first equation which can be written in the form $1-\gamma\left(P_{i, n}-\mathrm{C}\right)=0$ so $P_{i, n}=C+\frac{1}{\gamma}$. 